\title{
PARTIAL MIGRATION, AND LEK AND NESTING AREA FIDELITY IN FEMALE GREAT BUSTARDS ${ }^{1}$
}

\author{
Juan C. Alonso and Manuel B. Morales \\ Museo Nacional de Ciencias Naturales, CSIC, José Gutiérrez Abascal 2, 28006 Madrid, Spain, \\ e-mail: jcalonso@mncn.csic.es \\ JAVIER A. Alonso \\ Departamento de Biologia Animal, Facultad de Biología, Universidad Complutense, 28040 Madrid, Spain
}

\begin{abstract}
We examined the seasonal movements of wing-tagged and radio-marked adult female Great Bustards Otis tarda in a population in northwestern Spain. Four different movement patterns were found: females that migrated between breeding and wintering areas $(20 \%)$, females that only left their year-round home range area to mate $(32 \%)$, females that migrated from a wintering-mating area to a nesting-summering area (16\%), and females that stayed all year round within a relatively small home range area (32\%). All females displayed fidelity to their nesting and wintering areas, and most also showed fidelity to their leks. Migration patterns were not affected either in timing or distance by breeding success. The maximum distance between natal and dispersal locations during their first year of life was significantly higher in migratory females than in sedentary ones. These patterns explained the seasonal variations in population numbers observed in the study area. Surveys showed that the number of females increased from $600-700$ breeding birds, with $1,000-1,100$ birds present from October to March.
\end{abstract}

Key words: Great Bustard, lek fidelity, nest area fidelity, Otis tarda, partial migration, seasonal movements.

\section{INTRODUCTION}

Animals repeating a yearly round trip between breeding and wintering areas are considered to be migratory (Sinclair 1983). However, individuals belonging to different populations within the same species may perform migratory movements of different magnitude. Terrill and Able (1988) classified migratory patterns in birds as annual, partial, or differential. They applied the term "annual migrant" to species or geographically defined breeding populations in which all individuals migrate each year from their breeding sites, "partial migrant" to populations in which some individuals do and some others do not migrate from the same breeding area (Gauthreaux 1982, Lundberg 1988), and "differential migrant" to populations in which some classes of individuals (ages, sexes, or others) differ in timing of migration, distance traveled, or both (Gauthreaux 1982, Ketterson and Nolan 1983). Recent studies have shown that several species formerly defined as strictly migratory or sedentary exhibit significant interindividual variation in their movement patterns (Cade and Hoffman 1993, Schroeder and Braun 1993).

\footnotetext{
${ }^{1}$ Received 15 February 1999. Accepted 14 October 1999.
}

The Great Bustard (Otis tarda) has been traditionally considered as sedentary in the western and southern parts of its range, and migratory elsewhere (Gewalt 1959, Glutz et al. 1973, Cramp and Simmons 1980). However, some studies have reported seasonal changes in population numbers in different areas of the Iberian Peninsula, suggesting some movements do occur (Hidalgo and Carranza 1990, Alonso et al. 1995). Alonso et al. (1995) studied the extent of Great Bustard movements in the Reserve of Villafáfila (northwest Spain), which holds the densest population of the species in the world (Alonso and Alonso 1996); they examined sex differences in the distances traveled by radiomarked juveniles during dispersal, and also the extent of adult male postbreeding dispersal. These authors found that the maximum known distance traveled by adult males from leks after the mating season (up to $22 \mathrm{~km}$ ) was higher than that covered by females, which remained closer to their breeding areas. During that study, 3 of 10 adult males captured in the Reserve and tracked during one year spent the summer months outside the study area, returning between October and February. Moreover, seven birds wingtagged as young that established as breeders in the Reserve remained in their lek areas all year round, 
while another eight, also marked as juveniles, were regularly seen at their display sites only during the mating season. These then later moved out of the area to spend the rest of their annual cycle in some unknown place.

To date, no study has investigated in detail the individual variation in timing and spatial patterns of seasonal movements of adult females in this species. Here we describe different patterns of seasonal movements in female Great Bustards on the basis of marked birds and discuss them in relation to the following questions: (1) can these patterns explain seasonal changes in numbers of Great Bustards in this and other study areas? (2) Does a proportion of female birds migrate between breeding and winter areas? (3) Does lek distribution influence seasonal movements in females? (4) Does breeding success affect the timing and extent of female migration? (5) Do juvenile dispersal movements in females influence subsequent migration tendencies in any respect?

\section{METHODS}

\section{STUDY AREA AND SPECIES}

We carried out our study in the Wildlife Reserve of Villafáfila $\left(41^{\circ} 50^{\prime} \mathrm{N}, 5^{\circ} 35^{\prime} \mathrm{W}\right.$, about $700 \mathrm{~m}$ above sea level), which extends over $327 \mathrm{~km}^{2}$ of dry, treeless, and gently undulating farmland surrounding a group of small and shallow endorreic lagoons which cover 400 ha in the Province of Zamora, northwest Spain. The land is almost entirely cultivated with cereal (mainly wheat and barley, covering over $80 \%$ of the surface area of the Reserve) and alfalfa (about $8 \%$ ). Some minor crops are sunflower, rape, and vines. The remaining territory (about $9 \%$ ) is occupied by natural grassland used for sheep grazing. The climate is characterized by dry, hot summers and cold winters with moderate rainfall.

The Great Bustard is a ground dwelling, lekking bird which inhabits Palearctic natural and cultivated grasslands. It is a highly sexually dimorphic species, with adult males weighing between 10 and $15 \mathrm{~kg}$, and females only between 4 and $5 \mathrm{~kg}$. Males and females occur generally in separate flocks. Between late autumn and early spring, males concentrate at traditional arenas where they fight to establish a hierarchical rank and display in an exploded lek mating system (Gilliard 1969). Females also concentrate at these arenas between late March and early April to mate. They generally nest close to the lek where they copulate and take over all brood caring duties, usually rearing 1-2 chicks, rarely 3 . During the first three to four months of the chick's life, families are isolated, but then aggregate into larger flocks along with nonsuccessful females by early October. Most chicks, particularly female chicks, remain with their mothers until the following mating season, and female juveniles display strong natal philopatry, establishing as breeders in the neighborhood of the lek closest to their natal site. Between gaining independence from their mother and establishing as adult, there is a dispersal period where they may travel considerable distances (Alonso et al. 1998). In the first 4 months of life, chick growth rates are high and their diet is dominated by insects (Litzbarski and Litzbarski 1996). Probably due to the high nutritional needs of the offspring at this time, the home range of families reaches its largest size (ca. $3 \mathrm{~km}$ average diameter, Martín 1997), and so results in a decrease in the carrying capacity of the breeding habitat. Chick mortality also is high during this phase, 50-70\% in our study area (Martín 1997), and female lifetime breeding success is on average very low (Morales 1999).

\section{DATA COLLECTION AND ANALYSIS}

Each summer from 1983 to 1993, we captured young Great Bustards when they were still dependent on their mothers and weighed between 1 and $3.5 \mathrm{~kg}$. We marked a total of 188 birds (83 females) with patagial tags and in the last three years we also provided 101 of them (43 females) with either "poncho" (Amstrup 1980) or backpack harness-mounted radio-transmitters (Kenward 1980). Battery life was, respectively, 2 and 4 years on average, which allowed us to radio-track females from ground vehicles or aircraft continuously at least until their settlement as breeding adults (usually at age 2 years; Alonso et al. 1998). Once established, they could be regularly located by sight during regular surveys of the Reserve and its surroundings even when transmitter batteries had expired.

The surveys were carried out between January 1987 and March 1998, with a frequency that varied from one per week to one every 3-4 months, allowing us to both locate marked birds and monitor seasonal changes in this Great Bustard population. Some areas adjacent to the $\mathrm{Re}-$ 
serve also were surveyed, but less intensively. Each survey was made by four people in two cars over two consecutive days, following predetermined transects to cover the whole study area. The route was $384 \mathrm{~km}$ long and required $20 \mathrm{hr}$ per car to complete. Surveying was interrupted during midday hours (between 10:00 and 15:00), when the birds are usually inactive and thus difficult to see. Given the large size of Great Bustards, the excellent visibility conditions of the area, and the high density of tracks, we were confident that we sighted nearly $100 \%$ of the birds (Alonso and Alonso 1990). An exception to this was the number of females counted between early May and late July, when most of them are incubating in cereal. We assumed that female numbers during these months were the same as those counted in August-early September, when the cereal has been harvested. This assumption was supported by our observations of marked females, which remained approximately in the same areas through the summer. Our census results throughout the paper refer to females older than one year to avoid irregular variations in number of birds produced by variation in annual breeding success and by high mortality of young during the first months of life. Because first-year females are only recognizable in the field until late September, we assumed that the number of juvenile females counted in that month remained unchanged until the following June, thus subtracting that quantity from each monthly total of females between October and June. This is the closest possible approximation to the real number of females older than one year, because during that period only a negligible percentage of females die or disperse outside the Reserve (Martín 1997, Alonso et al. 1998). Monthly variation in Great Bustard numbers was analyzed with one way-ANOVA (Zar 1984).

For the analysis of seasonal movements of each marked bird, we needed to determine its nest site, and which lek was attended for copulation. We did not search actively for nests to avoid disturbance, but used three proxy variables as a substitute. These were, firstly, sites where females were seen occasionally during the incubation period, secondly, and more frequently, sites where mothers were first seen with their chicks, and finally sites where single birds were seen after having probably lost their clutch or brood. In a few cases in which we were able to find both nest site and later the female with the chick, these locations were less than $500 \mathrm{~m}$ apart (Alonso et al. 1998).

To determine which lek a female attended, we calculated its average location for the period of peak mating activity, which in our study area occurred between 25 March and 15 April (Morales 1999). The locations of the 11 Great Bustard leks in the Reserve and their area of influence after explosion were found from the census data and observations of marked males. These did not change throughout the study. Because our purpose was to describe movements of adult females, we used only data from birds older than two years. Each sighting of a marked female was plotted on a 1:50,000 map. Sightings of the same bird on the same day were averaged as one single data point, giving a total of 778 sightings. For each bird, we then calculated its average monthly location and from this point we measured linear distances to nest site and lek attended. Individuals that had no locations during one or more months were not considered, which reduced our final sample size to 25 females for which there were enough data to obtain the seasonal patterns of distances to nest and lek. We calculated the mean individual distances between wintering area (November-February), lek attended and nest, and classified a female as migratory (Fig. 3, patterns 1 and 3) if there was no overlap between its home ranges during the breeding season (April-August) and winter (November-February). Females with overlapping breeding and wintering ranges were classified as sedentary (Fig. 3, patterns 2 and 4). Within each of these categories we distinguished two different patterns according to the location of the lek attended: in migratory females, the lek area overlapped with the nesting range (pattern 1) or the wintering range (pattern 3), in sedentary females, the lek overlapped with the year-round home range (pattern 4) or was far from it (pattern 2). We tested the significance of the seasonal variation of distance to nest and lek with oneway ANOVA after log-transformation of the data.

To account for lek fidelity, we determined the lek attended by each female in successive years. We compared the proportion of females always sighted in the same lek during the mating season over several years with the proportion observed in more than one lek in different years by means of a $\chi^{2}$ test in which $50 \%$ was considered the 


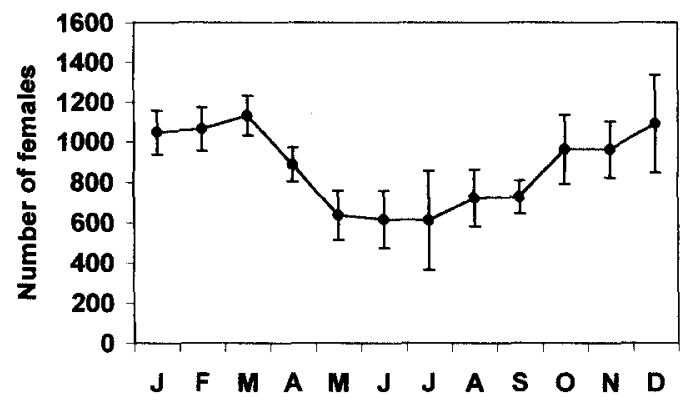

FIGURE 1. Mean monthly numbers ( $\pm 95 \%$ confidence intervals) of Great Bustard females older than one year censused in the Reserve of Villafáfila between January 1987 and March 1998 (49 counts). Monthly variation was highly significant $\left(F_{11,37}=10.1\right.$, $P<0.001$ ). All differences between winter (October to April) and summer (May to September) monthly means based on $\geq 3$ censuses were statistically significant (LSD-test, $P<0.05$ ).

expected frequency (Siegel and Castellan 1988). In a similar way, we determined the nesting area fidelity, counting the number of females that were sighted as solitary individuals on different years in the same or different areas (at $<2 \mathrm{~km}$ or $>2 \mathrm{~km}$ distance between locations, respectively) during the incubation period (generally between late April and early June) or rearing chicks during summer, as females do not abandon their nesting areas until young are about 4 months old (Martín 1997). For the purpose of nesting area fidelity, we also considered as nesting locations those areas where sightings of marked birds in small flocks were made until September, because neighboring females that have lost their broods aggregate into small flocks in the vicinity of their nesting sites. Finally, we also counted the number of females that visited the same or different wintering areas over several years.

To investigate the relationship between migratory behavior and the extent of movements undertaken by juveniles when they were still dependent on their mothers, we compared the maximum distances from their natal site traveled during their first year of life by sedentary females with the corresponding distance traveled by migratory females. We made this comparison in a sub-sample of 16 birds for which we were able to collect data for that period, using MannWhitney $U$-test (Zar 1984). Unless otherwise stated, values presented are means \pm SD.

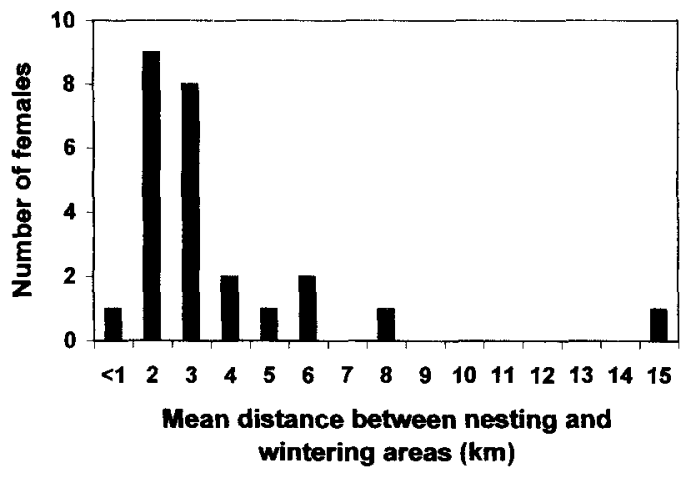

FIGURE 2. Frequency distribution of the mean distances between nesting (May) and wintering areas (November-February) of 25 individually marked Great Bustard females.

\section{RESULTS}

\section{SEASONAL CHANGES IN THE NUMBER OF FEMALES IN THE STUDY AREA}

The average number of females nesting in the Reserve, including both those with and without breeding success, varied around 635 birds (May counts, Fig. 1). Numbers remained more or less stable until October, when the female population increased significantly due to the arrival of many females that had lost their brood and a lower number of females with young. This increase continued until December-January, when peak numbers of around 1,100 females older than one year were reached. Numbers were stable until late March, and then decreased abruptly.

\section{MIGRATION PATTERNS OF MARKED FEMALES}

The frequency distribution of distances traveled by our sample of 25 marked females between wintering and nesting areas was right-skewed but not clearly bimodal (Fig. 2). Therefore, we used the overlap between wintering and nesting areas rather than just the distance as a criterion to distinguish between sedentary and migratory females. We distinguished four different patterns of seasonal movement (Fig. 3). In pattern 1, migratory females moved relatively long distances $(3-15 \mathrm{~km})$ between breeding areas (including mating in late March-early April and nesting and chick rearing from May to September) and non-overlapping wintering areas. In pattern 2 , females were sedentary but abandoned their year-round home area for a short time in late March-early April to mate at a distant lek (2$13 \mathrm{~km}$ ). In pattern 3 , females migrated only 

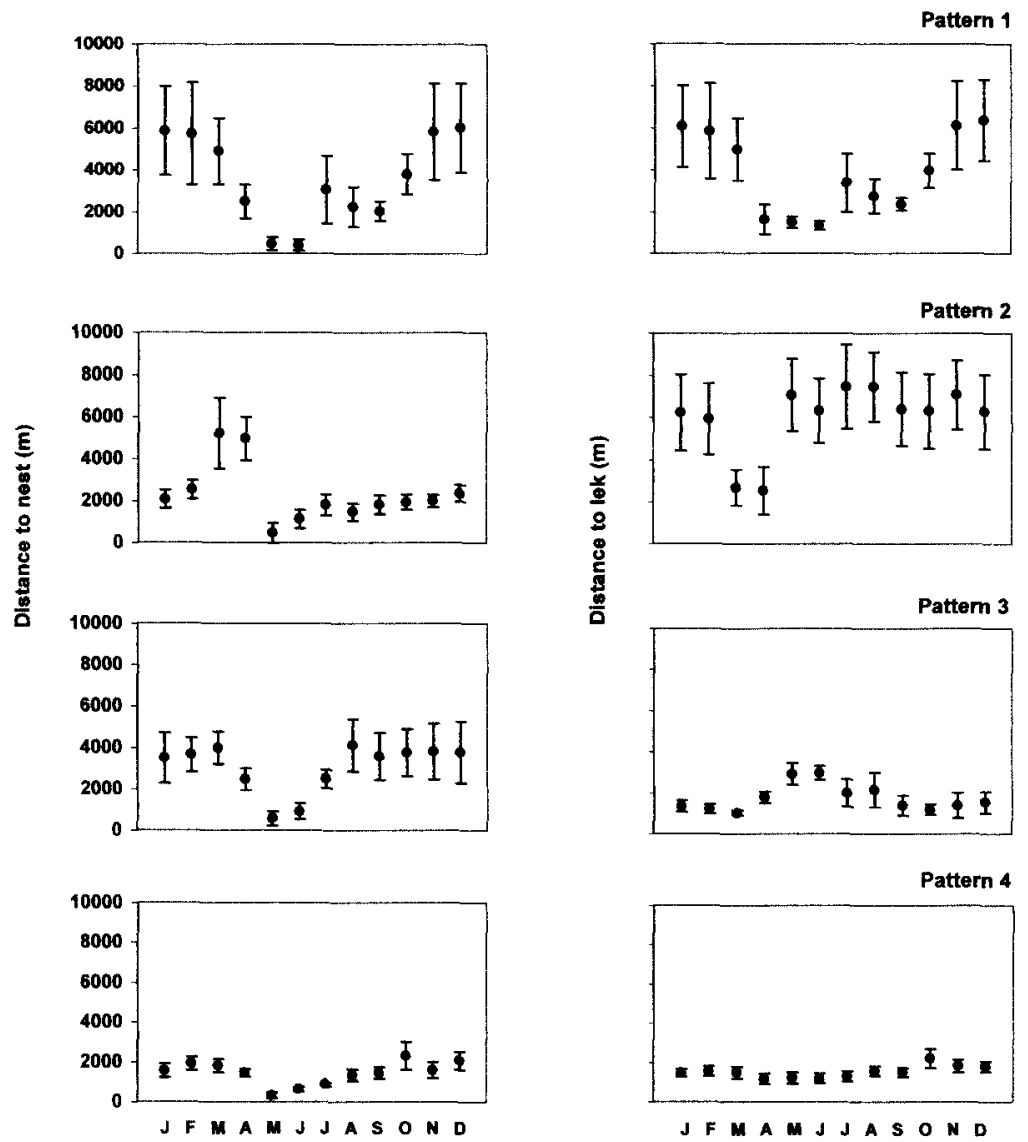

FIGURE 3. Patterns of monthly variation of mean distance ( \pm SE) to nest and lek of 25 marked, adult Great Bustard females. Seasonal variation was significant (ANOVA test) in all patterns with respect to nest (pattern $1, n=5$ females, $F_{11,48}=6.2$; pattern 2, $n=8$ females, $F_{11.84}=9.7$; pattern $3, n=4$ females, $F_{11.36}=3.24$; and pattern $4, n=8$ females, $F_{11.84}=7.7$, all $P<0.01$ ), and in patterns 1 and 2 with respect to lek (respectively, $F_{11,48}=3.3, P<0.002$, and $\left.F_{11,84}=3.2, P=0.001\right)$. Variation was marginally significant in pattern 3 with respect to lek $\left(F_{11,36}=1.9, P=0.08\right)$, and not significant in pattern $4\left(F_{11,84}=0.9\right)$.

short distances and lived within the lek area most of the year. They left it after mating to nest at close $(2-7 \mathrm{~km})$ but clearly differentiated, nonoverlapping areas and later returned. Finally, in pattern 4 , females were typically sedentary, staying all year round close to their breeding areas (mean monthly distances to nest and lek center $\leq 2 \mathrm{~km}$ ). All four patterns showed significant seasonal variation in distance to nest site. With respect to lek site, patterns 1 and 2 showed significant seasonal variation, pattern 3 was marginally significant, and pattern 4 was nonsignificant.

To illustrate the four patterns described above, we show the year round ranges of two females of each pattern in Figure 4. Females $A$ and $B$ were pattern 1 migrants. Both had a breeding (April to October) area, which included the mating site and the nesting area, and a distant, nonoverlapping wintering area (November to February). Interestingly, both females of this example wintered in the same area in the east of the study area, whereas they mated and nested far apart from each other. Females $C$ and $D$ were (sedentary) pattern 2 females that left their year round home range (May through February) to mate at a relatively distant lek. Females E and $F$ were short-distance, pattern 3 migrants that moved to a close nesting area outside the Reserve only during May-June and later returned to their usual home range. Finally, females $G$ and $\mathrm{H}$ were (sedentary) pattern 4 birds that nev- 
er left the vicinity of their mating and nesting areas, and occupied small home ranges.

\section{EFFECT OF BREEDING SUCCESS ON MOVEMENTS}

We compared the movement patterns of longand short-distance migrating females between years in which they bred successfully and years in which they did not (Fig. 5). Although sample sizes for successful years were too low to test for seasonal variation, with only two females with breeding success in each pattern, the migration patterns did not differ substantially in timing and distance of seasonal movements from years without breeding success.

\section{LEK, NESTING, AND WINTERING AREA FIDELITY}

Twenty-five out of 27 adult females (93\%) attended the same lek over several years. Twentyone out of $24(88 \%)$ showed fidelity to nesting area. These proportions differed statistically from the expected $50 \%\left(\chi^{2}{ }_{1}=72.6, P<0.001\right.$, and $\chi_{1}^{2}=56.25, P<0.001$, respectively). On the other hand, all nine females that performed seasonal movements between breeding and wintering areas (patterns 1 and 3 ) and were sighted over several wintering periods, visited the same wintering areas each year. Mean distance between breeding and wintering ranges of these nine females was $4.9 \mathrm{~km}$ (range 2.9-14.5 km).

When we compared the maximum distance from the natal site traveled during their juvenile dispersal phase in migratory females (patterns 1 and 3) with that of sedentary females (patterns 2 and 4), we found that it was significantly higher for migratory $(8.7 \pm 5.0 \mathrm{~km}, n=6)$ than for sedentary individuals $(4.3 \pm 3.3 \mathrm{~km}, n=10$; Mann-Whitney $U=2.06, P<0.05$ ).

\section{DISCUSSION}

The results of this study show the diversity of seasonal movement strategies undertaken by different female Great Bustards within the same population. The frequency distribution of the mean distances separating wintering and nesting areas in our sample of marked females was clearly right skewed, ranging up to $14.5 \mathrm{~km}$, but not completely bimodal, preventing a clearcut distinction between migratory and sedentary birds. However, using the criterion of overlap between nesting and wintering areas, we distinguished 9 migratory from 16 sedentary birds.
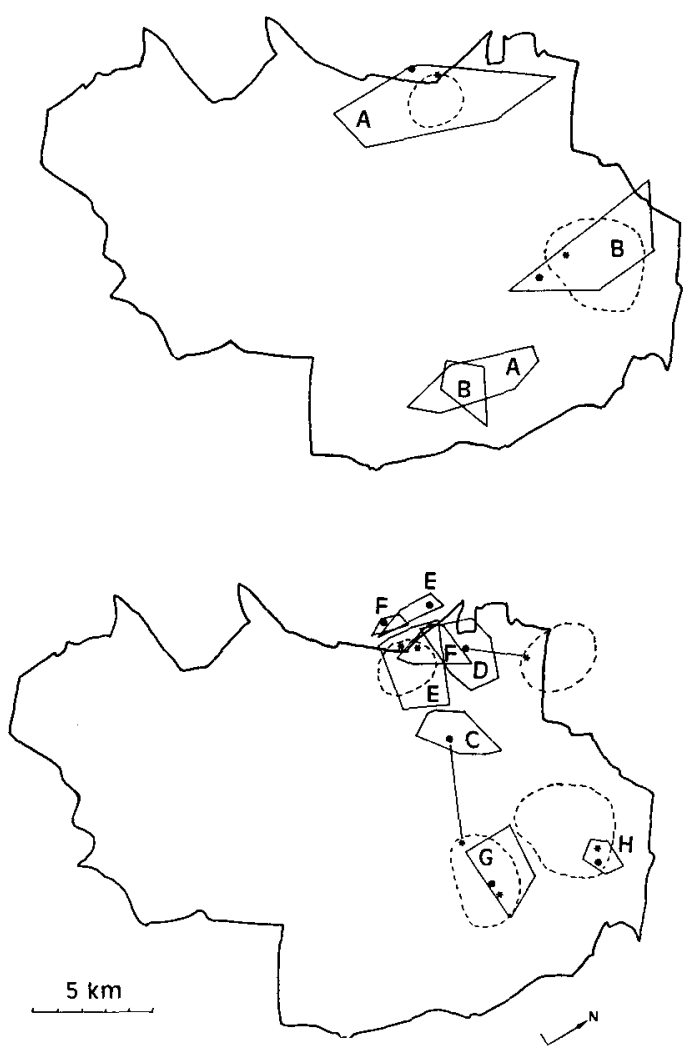

FIGURE 4. Sketch maps of the Reserve of Villafáfila showing the home ranges, calculated as the maximum convex polygon, of eight marked adult Great Bustard females selected to illustrate patterns $1-4$ of seasonal movements represented in Figure 3. Dots represent the nesting sites of each female and asterisks the estimated mating localities, in both cases calculated as means for the various years with data. The exploded lek each female visited for mating is encompassed by a dashed line. Females A (28 sightings, April 1993-March 1996) and B (17 sightings, April 1992-October 1996) were typical migratory individuals (pattern 1), with non-overlapping breeding and wintering areas; females C (41 sightings, July 1992-August 1995) and D (17 sightings, April 1991-October 1996) followed pattern 2 , leaving their year round home range to mate at a distant lek in March-April; females E (14 sightings, March 1994-March 1996) and F (54 sightings, July 1993-January 1997) were two short-distance migrants that moved to a close nesting area, following pattern 3 ; and females G (45 sightings, November 1987March 1998) and H (19 sightings, August 1993-March 1998) were typically sedentary.

Within each of these two patterns, an additional displacement behavior to the lek for mating allowed a distinction of an additional two patterns. of the four patterns described, two could be considered migratory (patterns 1 and 3 , followed 


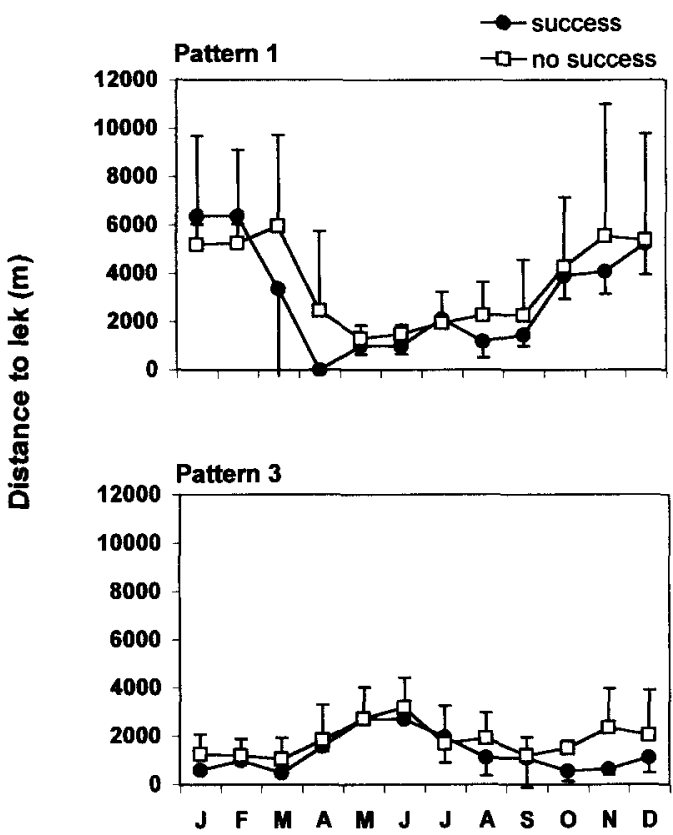

FIGURE 5. Patterns of monthly variation of mean distance to lek ( \pm SD) in typical (pattern 1) and shortdistance (pattern 3) migrant females in relation to their breeding success: series of black dots represent seasonal movements in years in which they reared one chick ( $n=2$ females for each pattern), and series of open squares represent movements in years without breeding success. Seasonal variation was significant for females of both patterns in unsuccessful years (pattern $1, n=4$, Kruskal-Wallis $\chi^{2}{ }_{9}=33,6, P<0.001$; pattern $3, n=2, \chi^{2}{ }_{9}=17.4, P<0.05$ ).

respectively by $20 \%$ and $16 \%$ of our sample of 25 marked birds) and two as sedentary (patterns 2 and 4, each followed by $32 \%$ of birds).

Between both migratory, as well as between both sedentary patterns, there were marked differences that could reflect their different origin. All four patterns are probably determined by a combination of two main behavioral responses due to food selection pressures (Lundberg 1987, 1988, Terrill 1990). Female Great Bustards following pattern 1 moved between distant wintering and breeding (including mating and nesting) areas, and so performed true migratory movements. Moreover, all of these females used the same wintering areas on consecutive years. On the other hand, females following pattern 3 spent most of the year in the close vicinity of their leks and moved only after mating to nest in a near, although clearly differentiated, nesting area. They then moved gradually back to their winter ranges, after the young-rearing phase in early summer. This kind of movement also resembles migration but might be better interpreted as a nesting dispersal movement resulting from the need for a territory large enough for rearing young.

As for the sedentary birds, females following pattern 2 approached leks from distant yearround home ranges just for mating and so we did not classify this behavior as a typical migratory pattern. Bird surveys and mapping of leks in the Reserve (Morales 1999) showed that most of these females lived in areas where no males were found at any time of the year and which were quite distant from any lek site, being therefore forced to travel relatively long distances to copulate (e.g., birds C and D, Fig. 4). True sedentary females (pattern 4) performed only short distance movements within a small radius (1-2 $\mathrm{km})$ around their nesting site.

These movement patterns were consistent with the seasonal variation in numbers described in Figure 1. The lower numbers of adult females nesting in the Reserve with respect to those wintering in it (600-700 birds compared to 1,0001,100 in winter), and the territorial behavior of females during the first four months of the chick rearing period when the families' diet is dominated by insects (Martín 1997, Lane et al. 1999), suggest that the female population breeding in the Reserve might be close to the carrying capacity at that time of the year. According to this interpretation, many females wintering in the Reserve could be forced to leave the neighborhood of their leks to nest elsewhere. Nevertheless, we acknowledge the small sample size on which pattern 3 is based and that conclusions derived from it should therefore be taken cautiously. Further study will show how prevalent this pattern is.

In winter, females concentrate in the study area seeking the optimal feeding conditions provided by the high number of alfalfa fields, which adult Great Bustards select as their most preferred winter food (Alonso and Alonso 1990, Lane et al. 1999). Such increase in winter numbers and the subsequent decrease between April and May, reaching minimum numbers from May to September (650-750 adult females), is largely explained by females following both migration patterns described in this study: those entering the Reserve only for the winter (pattern 1), and those wintering and mating in the Reserve and 
leaving it only to nest and rear their young outside (pattern 3, see for example birds $\mathrm{E}$ and $\mathrm{F}$ in Fig. 4). Some females following pattern 2 (those approaching the lek in late March just for mating) also contributed to the population increase detected in the Reserve in March, as the study area has a higher lek density compared to the region around it, and there are only two leks in the immediate vicinity $(<15 \mathrm{~km})$ of the Reserve. Although the copulation period extends through the first days of April, the mean number of females in that month is lower than in March because females disperse from the lek to their nesting sites soon after mating.

In relation to lek fidelity, we conclude that adult female Great Bustards demonstrated fidelity to the leks they visited at the age of two years. In a previous study we showed that most females were strongly philopatric and usually mated at the lek closest to both their natal site and nesting site (Alonso et al. 1998). Nesting area fidelity seems also to be the usual behavior among females in this species, given that the mean distance between all locations of a female during consecutive years was smaller than the mean family home range for one season (Martín 1997). Both fidelity tendencies strongly contributed to the significance of the first three patterns, both for females that always nested in the vicinity of the lek as well as for females that visited a distant lek just for mating. Lek fidelity in patterns 1,3 , and 4 obviously caused females to always visit the closest lek. This result was contrary to predictions by the "hot-spot" model of lek evolution (Bradbury and Gibson 1983, Bradbury et al. 1986), in which females are expected to encompass more than one lek in their home ranges and to visit more than one lek before mating, but partially supports the "female preference" hypothesis (Bradbury 1981, Bradbury and Gibson 1983, Beehler and Foster 1988), in which females will attend only one lek and always the closest one to their nesting areas. On the other hand, females following pattern 2, in spite of the long distance traveled, did not visit several leks either, but moved directly to the same one each year, which was usually the closest to their year-round home ranges (Morales 1999). However, as we have observed, several females living in an area with no nearby lek may move to different, although more or less, equidistant leks. This strong lek site-fidelity may to a great extent limit the range of female Great
Bustard seasonal movements and could be influenced by the strong natal philopatry also displayed by female Great Bustards which generally settle as adults in the vicinity of the closest lek to their natal nests (Alonso et al. 1998).

The coexistence of migratory and sedentary birds indicates partial migration (Terrill and Able 1988) as the general pattern of movements of female Great Bustards in the Villafáfila population. Partial migration has been reported in several other bird species, and particularly in other lekking or polygynous terrestrial birds previously considered sedentary, such as several grouse species (Schroeder 1985, Cade and Hoffmann 1993, Schroeder and Braun 1993). We believe that this might indeed be the dominant movement pattern in most other Great Bustard populations as well as in other bustard species such as the Little Bustard (Tetrax tetrax) and the Houbara Bustard (Chlamydotis undulata, Cramp and Simmons 1980, Osborne et al. 1997), which also are usually reported as sedentary in large regions of their distribution range. Moreover, the coexistence of long and short-distance migrants in the Great Bustard population of Villafáfila suggests a differential migration pattern (Ketterson and Nolan 1983, Terrill and Able 1988). Such combination of partial and differential migration has been described, for instance, in the Spruce Grouse (Falcipennis canadensis), in which short distance migrant females moved less than $2 \mathrm{~km}$ (Schroeder 1985), and the Blue Grouse (Dendragapus obscurus), in which all birds that traveled more than $3 \mathrm{~km}$ were considered as long-distance migrants (Cade and Hoffmann 1993).

How can these intrasexual differences in seasonal movements in female Great Bustards be explained? Migratory behavior in the grouse has been proposed to retrace movements by yearlings during juvenile dispersal (Schroeder 1985, Cade and Hoffmann 1993, Schroeder and Braun 1993). Such might also be the case in Great Bustard females, where young females depend on their mothers and follow them for about one year (Alonso et al. 1998). The fact that maximum distances traveled during the first year of life were significantly higher in females that would later follow a migratory pattern than for those that would remain sedentary suggests this might be a factor contributing to adult migration tendencies. Thereafter, birds remain faithful to the area first selected, and neither site fidelity 
nor timing of seasonal movements in migratory females would be affected by breeding success. Furthermore, the only two females performing a natal dispersal movement (Alonso et al. 1998) showed some migratory behavior as adults, as their mothers did. These results support the existence of either a mixed evolutionarily stable strategy with two phenotypic tactics, migrant and resident, based on learning from the mother (Lundberg 1988), or genetic polymorphism, in which two morphs occur in the population, whose behaviors do not change, irrespective of variation in environmental conditions (Biebach 1983). However, the alternative hypothesis of a conditional strategy based on individual asymmetries such as age, sex, and dominance (Greenwood and Harvey 1982, Ketterson and Nolan 1983, Lundberg, 1987, 1988) cannot be excluded without precise measurements of survival and breeding success.

\section{ACKNOWLEDGMENTS}

We thank the 42 Group of the Spanish Air Forces Getafe base for their generous collaboration in helping to locate radio-tagged birds, and Enrique Martín for his help during fieldwork. V. Ena and co-workers marked some of the young. L. M. Bautista, H. Bustami, C. Caldero, A. Correas, I. Martín, and M. A. Naveso helped us capture birds. C. A. Martín took part in some surveys and helped us with radio-tracking during the last two years of study. The comments of two anonymous referees and $\mathrm{S}$. J. Lane improved the manuscript. Field work was financed by the Dirección General de Investigación Científica y Técnica, the Instituto Nacional para la Conservación de la Naturaleza, and the Junta de Castilla y León. M. B. Morales benefited from a predoctoral fellowships from the Consejería de Educación de la Comunidad de Madrid-Museo Nacional de Ciencias Naturales (CSIC). This study is a contribution to DGICYT project PB94-0068.

\section{LITERATURE CITED}

Alonso, J. C., And J. A. Alonso [eds.]. 1990. Parámetros demográficos, selección de hábitat y distribución de la avutarda en tres regiones españolas. ICONA, Madrid.

Alonso, J. C., ANd J. A. Alonso, 1996. The Great Bustard (Otis tarda) in Spain: present status, recent trends and an evaluation of earlier censuses. Biol. Conserv. 77:79-86.

Alonso, J. C., J. A. Alonso, E. Martín, and M. B. Morales. 1998. Proximate and ultimate causes of natal dispersal in the Great Bustard. Behav. Ecol. 9:243-252.

Alonso, J. C., E. Martín, J. A. Alonso, and M. B. MoRALEs. 1995. Range and patterns of Great Bustard movements at Villafáfila, NW Spain. Ardeola 42:69-76.
Amstrup, S. C. 1980. A radio-collar for game birds. J. Wildl. Manage. 44:214-217.

Beehler, B. M., AND M. S. Foster. 1988. Hotshots, hotspots and female preferences in the organization of lek mating systems. Am. Nat. 131:203219.

BIEBACH, H. 1983. Genetic determination of partial migration in the European Robin (Erithacus rubecula). Auk 100:601-606.

BradbuRY, J. W. 1981. The evolution of leks, p. 138169. In R. D. Alexander and D. W. Tinkle [EDS.], Natural selection and social behavior. Chiron Press, New York.

Bradbury, J. W., AND R. M. Gibson. 1983. Leks and mate choice, p. 109-138. In P. Bateson [ED.], Mate choice. Cambridge Univ. Press, Cambridge.

Bradbury, J. W., R. M. Gibson, and I. M. Tsai. 1986. Hotspots and the dispersion of leks. Anim Behav. 34:1694-1709.

Cade, S. B., and R. W. Hoffman. 1993. Differential migration of Blue Grouse in Colorado. Auk 110: 17-77.

Cramp, S., AND K. E. L. Simmons [EDS.]. 1980. The birds of the Western Palearctic. Vol. 2. Oxford Univ. Press, Oxford.

Gewalt, W. 1959. Die Großtrappe. Die Neue BrehmBücherei, Wittemberg-Lutherstadt, Germany.

Gilliard, E. T. 1969. Birds of paradise and bowerbirds. Weidenfeld and Nicholson, London.

Glutz, U. N., K. M. Bayer, AND E. BezZel. 1973. Handbuch der Vögel Mitteleuropas. Vol. 5. Akademische Verlagsgesellschaft, Frankfurt a. M.

GauthreauX, S. A., JR. 1982. The ecology and evolution of avian migration systems, p. 93-168. In D. S. Farner, J. R. King and K. C. Parkes [Eds.], Avian biology. Vol. 6. Academic Press, New York.

Greenwood, P. J., AND P. H. HaRvey. 1982. Natal and breeding dispersal in birds. Annu. Rev. Ecol. Syst. 131:1-21.

Hidalgo, S. J., and J. Carranza. 1990. Ecología y comportamiento de la avutarda (Otis tarda). Universidad de Extremadura, Cáceres, Spain.

Kenward, R. E. 1980. Radiomonitoring birds of prey, p. 97-105. In C. J. Amlaner and D. W. McDonald [EDS.], A handbook on biotelemetry and radiotracking. Pergamon Press, Oxford.

Ketterson, E. D., and V. NOLAN JR. 1983. The evolution of differential bird migration. Current Ornithol. 1:357-402.

Lane, S. J., J. C. Alonso, J. A. Alonso, and M. A. NAVESo. 1999. Seasonal changes in diet and diet selection in a great bustard population in northern Spain. J. Zool. 247:201-214.

LitzBarski, B., AND H. Litzbarski. 1996. Einfluß von Habitatstruktur und Entomofauna auf die Kükenaufzucht bei der Großtrappe (Otis tarda L., 1758). Natursch. Land. Brand. 5:59-64.

LundBerg, P. 1987. Partial bird migration and evolutionary stable strategies. J. theor. Biol. 125:351360 .

LUNDBERG, P. 1988. The evolution of partial bird migration. Trends Ecol. Evol. 3:172-175.

MARTín, E. 1997. Dispersión juvenil y cuidado mater- 
nal en la avutarda (Otis tarda). Ph.D. diss., Univ. Autonóma, Madrid.

Morales, M. B. 1999. Ecología reproductiva y movimientos estacionales en la avutarda (Otis tarda). Ph.D. diss., Univ. Complutense, Madrid.

OsBorne, P. E., M. Al BowARDI, AND T. BAILEY. 1997. Migration of the Houbara Bustard Chlamydotis undulata from Abu Dhabi to Turkmenistan: the first results from satellite tracking studies. Ibis 139:192-196.

Schroeder, M. A. 1985. Behavioral differences of female Spruce Grouse undertaking short and long migrations. Condor 87:281-286.

Schroeder, M. A., ANd C. E. Braun. 1993. Partial migration in a population of Greater PrairieChickens in northeastern Colorado. Auk 110:2128.
Siegel, S., and Castellan, N. J. 1988. Nonparametric statistics for the behavioral sciences. 2 nd ed. McGraw Hill, New York.

SinClaIR, A. R. E. 1983. The function of distance movements in vertebrates, p. 240-258. In I. R. Swingland and P. J. Greenwood [EDS.], The ecology of animal movements. Clarendon Press, Oxford.

Terrill, S. B. 1990. Food availability, migratory behavior, and population dynamics of terrestrial birds during the nonreproductive season. Stud. Avian Biol. 13:438-443.

Terrill, S. B., AND K. P. ABLE. 1988. Bird migration terminology. Auk 105:205-206.

ZAR, J. H. 1984. Biostatistical analysis. 2nd ed. Prentice Hall, New York. 